\title{
The Family Support Group (FSG) Leaders' Handbook
}

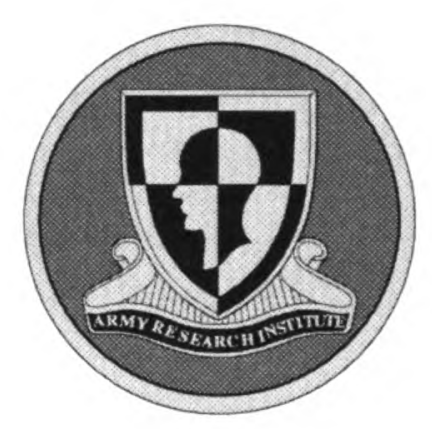

\section{U.S. Army Research Institute}

for the Behavioral and Social Sciences

\section{Walter R. Shumm \\ Kansas State University}

D. Bruce Bell

and

Lynn M. Milan

U.S. Army Research Institute
Mady W. Segal

University of Maryland

Organization \& Personnel Resources Research Unit

Paul A. Gade, Chief

Study Report 2000-02

April 2000

Approved for public release; distribution is unlimited. 